Self-funded leave and life role development 1

Running head: SELF-FUNDED LEAVE AND LIFE ROLE DEVELOPMENT

Dale S. Furbish

Auckland University of Technology 
Self-funded leave and life role development 2

\begin{abstract}
Self-funded leave is an employee benefit that provides a time resource to workers who wish to develop interests and non-work-life roles. This article reports the results of qualitative research conducted on 16 workers who completed a self-funded leave program. Semi-structured interviews were used to explore participants' motivations to enroll in the self-funded leave program, how the leave contributed to work-life balance through development of non-work life roles, and difficulties that arose during participation in the self-funded leave program. Results reveal that participants did use self-funded leave to improve their work-life balance and augment other life-roles. However, unpredicted events influenced how the leave time was actually used, which was often different from original plans and goals. Adult transition theory is used to conceptualize the process of participating in self-funded leave and to suggest how employees who undertake self-funded leave can be best supported by career counselors.
\end{abstract}


Self-funded leave and life role development 3

\section{Self-Funded Leave and Life Role Development}

Work-life balance is a topic of great interest in contemporary career literature (Gambles, Lewis, \& Rappoport, 2006; Glynn, Steinberg, \& McCartney, 2002; Greenhaus \& Beutell, 1985; Hall, 1990; Halpern \& Murphy, 2005; Pocock, 2003). Discussions about work-life balance validate the multi-faceted lives that workers live and the difficulties that can arise when work roles displace other life roles. Neault (2005) asserted that,

Regardless of one's personal definition for balance, most people know when they are out of balance; they are constantly tired, feel as if their choices are limited, have minimal control, and are no longer able to effectively manage their lives. (p. 1)

Time spent in the worker role is often the critical variable. When an employee devotes inordinate time and energy to work, the personal resources available for the fulfillment of other life roles are correspondingly reduced. Balance becomes jeopardized. Resulting imbalance is likely to produce conflict between work and other life roles as well as an overall low quality of life (Greenhaus, Collins, \& Shaw, 2003).

Employers have a stake in reducing employee work-life role conflicts. Allen, Herst, Bruck, and Stutton (2000) found that such conflicts result in negative consequences not only for individual employees, but also for the employing organization. Numerous strategies exist for an employer to promote balance. Employees may be offered benefits such as flexible scheduling, telecommuting, day-care, or eldercare assistance (Lobel \& Kossek, 1996). Greenhaus and Foley (2007) classified strategies for assisting employees to maintain work-life balance as formal and informal employment 
Self-funded leave and life role development 4

practices, alternative work arrangements, dependent care support, information, financial aid, work flexibility, support, and reduced work hours.

Time to engage in desirable or necessary life roles other than employee is an essential commodity for establishing work-life balance. Therefore, of the various strategies for addressing work-life balance, leave programs are among the most popular and potentially most effective. Leave is usually granted (and is often legislated) by an employer when events such as the birth of a child (parental leave) or the death of a close relative (bereavement leave) occur and thereby affect an employee's life roles. Another common leave option is educational leave, which is typically granted so that an employee can engage in study or training to enhance job performance. Some employers also grant unpaid leave, during which an employee does not receive a salary but is assured of return to employment at the end of the leave period.

A sabbatical is a special type of leave that has been historically offered to academics in higher education institutions. Sabbaticals have existed in higher education since at least the end of the nineteenth century (Kimball, 1978), but are becoming increasingly available in other employment environments such as business (Carr \& Tang, 2005), secondary schools (Gaziel, 1995), nursing (Keleher, 1993), and libraries (Hubbard, 2002). Sabbaticals release employees from normal duties for the purpose of engaging in research, professional development, or other professionally renewing activities. Among the outcomes cited are increased job satisfaction; personal and professional growth, and rejuvenation; focused time for improving teaching, research, and service; new perspective and attitudes; improved mental and physical health; 
Self-funded leave and life role development 5

increased energy and enthusiasm; and producing scholarly/creative products (Benshoff \& Spruill, 2002; Boening \& Miller, 1997; Cook , 1994; Sima, 2000; Zahorski, 1994).

While the benefits of sabbatical programs for both individuals and organizations are well established, traditional sabbaticals have "strings attached.” Some of the typical requirements are that sabbaticals are usually available only to professionals or senior staff within an organization. Second, the individual is required to qualify for a sabbatical based on length of service, rank, etc. Third, some sort of academic or professional output is usually expected as a result of the sabbatical. Last, since (reduced) salary is often paid by the employer during the sabbatical, there is a requirement that the sabbatical taker return to employment for a specific period or else salary must be repaid.

An alternative to the traditional sabbatical is a self-funded leave. Self-funded leaves also provide time to an employee, but are more flexible in that no specific leave outcomes or eligibility are required by the employer. Employees therefore have maximum self-determination for how the leave time is spent. Because of this feature, the leave-taker can use the time for whichever purposes are most desired. Further, employers who offer self-funded leave recognize that employers benefit from broadened staff perspectives and renewed vigor (Auckland University of Technology, n.d.).

A common structure for self-funded leave plans is for an employee to set aside $20 \%$ of salary for 4 years. During the $5^{\text {th }}$ year, the employee takes a leave of absence and receives $80 \%$ of the most recent salary (i.e., the salary received during the $4^{\text {th }}$ year). This scheme is often called the 4 for 5 plan. Another option is for an employee to set aside $20 \%$ of salary for $2 \frac{1}{2}$ years, then take a 6 month leave of absence, again at $80 \%$ salary for the term of the leave. This variant is known as a 2 for $2 \frac{1}{1} 2$ leave. Where self-funded 
Self-funded leave and life role development 6

leave is available, it is usually open to all full-time employees, regardless of job title or level.

Despite the apparent potential of self-funded leave for contributing to work-life balance, it is not generally available to employees. Perhaps the largest employer who offers self-funded leave is the Canadian Government (Treasury Board of Canada Secretariat, 1997). Otherwise, self-funded leave programs do not appear to be available in many other organizations. Moreover, systematic study of self-funded leave could not be located through literature searches.

The purpose of this study was to investigate how employees who participated in a self-funded leave program used the time away from work and the implications for worklife balance. Super’s (1976) notion of life roles provides a useful framework for consideration of the events during self-funded leave.

\section{Life Role Theory}

Super (1976) first proposed the life-career rainbow model to comprehensively convey the structure and nature of career. Fundamental to this model was recognition that career is comprised of socially defined life roles, with worker being only one of many that a person simultaneously occupies. Other life roles that an individual may inhabit are child, student, leisurite, citizen, spouse, parent and homemaker, and pensioner. Super noted that other life roles may also be identified, although the above noted roles are highlighted on the rainbow model. Sibling, worshiper, lover, reformer, criminal are other roles that he suggested. Regardless of the specific roles and the sequence in which they appear during life, "The constellation of interacting, varying roles constitutes the career" (Super, 1980, p. 284). 
Enactment of the various roles that an individual may possess at a given time also has a temporal aspect. For example, not everyone marries and some people die before retirement. Also, the saliency or importance that each life role has at a given time varies. The role of parent is usually of greater salience when children are young and living at home than after they leave home. Because people fulfill multiple roles, the time spent in one role takes away time from others. Super recognized that the "The number of hours in day, the number of days in a month and in a year...set limits to the degree to which the simultaneous and sequential proliferation of roles produces role conflict or results in selfactualisation and satisfaction” (Super, 1980, p. 287). Although Super did not use the terminology, his statement is seminal for consideration of work-life balance.

\section{Method}

In order to examine the life roles that individuals occupy during self-funded leave plans and better understand how self-funded leave contributes to work-life balance, a study was conducted on the experiences of a group of university employees who completed either a 4 for 5 or a 2 for $2 \frac{1}{2} 2$ self-funded leave program.

Three main research questions were of interest. Research Question 1: What were the motivations of participants for undertaking a self-funded leave and did self-funded leave fulfill the purposes of the leave? Research Question 2: How did participants use the period of self-funded leave to pursue life roles and interests that were constrained during full-time employment? Research Question 3: What problems were experienced by participants during self-funded leave and how could they be best supported during the entire span of preparation, leave, and return to work?

\section{Participants}


Self-funded leave and life role development 8

Participants of this study were employees of a large urban New Zealand university who had completed a self-funded leave program. Twenty-two potential participants were identified by the university’s human resources office. Of these, 16 agreed to be interviewed. Both teaching and non-teaching employees were represented. Nine of the participants held academic (teaching) contracts and 7 held administrative (non-teaching) contracts. Participants included senior lecturers, librarians, administrative staff, student services staff, and maintenance staff. Ten participants had completed the 2 for $2 \frac{1}{2}$ self-funded leave program and seven had completed the 4 for 5 program. One participant had completed both options.

\section{Procedure}

A qualitative research approach was employed. Interviews were conducted using a semi-structured interview protocol. Questions used in the interview were designed to solicit accounts of the entire self-funded leave experience, commencing with the initial decision to participate through completion of the leave and return to work. Interview notes were made during the interview and the interviews were audio recorded.

\section{Results}

Analysis of the data indicated the following findings for each research question. Research Question 1: The participants unanimously reported satisfaction with self-funded leave. A variety of motivations to enroll in the leave programs were expressed. Personal renewal was a goal for many of the participants. Participants reported "burn-out" in their position, needing a break, opportunity to reenergize their career, restore work-life balance, and reclaim career on own terms. Other participants expressed more exact goals for enrolling in the self-funded leave program. The specific purposes for the self-funded 
leave included traveling overseas, overseeing construction of a house, completing an academic qualification, fulfilling a life-long goal (taking the Trans-Siberian rail journey), writing a book, previewing retirement, and immersing a young daughter in the family's native culture.

Research Question 2: Some differences in the specific goals of the participants were linked to their job in the university. Participants on teaching contracts were more likely to engage in academic pursuits such as completing a degree or writing a book or journal article. However, there were more commonalities than differences between participants on teaching contracts and non-teaching contracts. Role shifts from worker to other roles that would ordinarily compete with work roles were the over arching motivation for participating in the leave.

Research Question: Finances were reported as the greatest concern while participating in self-funded leave. Because self-funded leave programs require participants to contribute $20 \%$ of salary during the build up period (either $2 \frac{1}{2} 2$ or 4 years depending on the program option) and then receive reduced salary during the leave period itself (a further 6 or 12 months), participants faced lower salary over a significant period. Living on $80 \%$ of salary during the leave lead-up period was difficult for many of the participants. Indeed, some participants reported that they began the program and had to withdraw due to financial reasons before they eventually re-enrolled for the program and completed the leave. Having the financial resources to fulfill goals during the leave period was difficult and resulted in modifying activities during the leave period. Examples were lessening travel while on leave, or taking other employment during the leave period to meet financial obligations. 
The period of leave had major impacts on the life roles of all participants. As would be expected, each reported a reduction in their role of worker (employee). However, since self-funded leave policies do not prohibit employment during the leave, some participants did work in other jobs. None of the jobs were full-time. The motivation for some participants who took another job while on leave was to increase income. Others who took other employment while on leave wished to gain experience in another occupation. Many participants purposefully used the increased time available to them during leave to heighten their role of parent and spouse. For these participants, an intended outcome of the leave was to spend more time with families whom they felt were neglected because of normal work demands. This goal was reported by both male and female participants.

Unplanned events during the leave resulted in increased salience of some life roles for some participants. In these instances, the role of grandparent was highlighted when their children became parents during the participants' leave. Roles of child (son/daughter) became more important for some participants whose parents became ill and required care.

Leisurite roles were augmented and leave takers used leave time to learn new past-times such as golf and Tai Chi. Student roles for some became more salient as a result of studying to complete an academic qualification or through self-interest study of other languages and political science. Changes in citizen roles were typified by increases in volunteer activities. The leave provided time for some to complete household projects, thus modifying their homemaker role. 
The capacity to self-determine use of time during the leave was the most consistently reported benefit that resulted from participation in the self-funded leave. All participants viewed self-funded leave as a personally positive experience and all indicated that they would recommend the program to others. Participants reported that they felt renewed after returning to work. In some instances, there were reports that supervisors better appreciated the participants upon return from leave. Reports that participants returned to work with new skills or perspectives gained during the leave period were common.

Nonetheless, some participants reported negative aspects. Some felt that changes occurred in their university departments while they were on leave and they had no input to these changes. Others suggested that being on an extended leave was viewed negatively by their colleagues and supervisors and was an impediment to their professional career progression. A few participants who have teaching roles and who were on leave during the first 6 months of the academic years reported difficulties with re-entering teaching in the middle of the year. For some, there was a feeling of dread when returning to a work schedule after the flexibility of self-designed time utilization.

Participants identified advantages and disadvantages to their employer as a result of their self-funded leave. Participants suggested that staff who replaced them while they were away gained experience in new roles. By trialing new job roles, replacement staff gained insight into their career progression and possible succession into future job roles. The employer gained the good will of staff who participated in the program. The positive feelings generated staff loyalty and likelihood of continuing employment at the university. Participants also noted that they believed self-funded leave programs were an 
attraction to others considering applying for employment to the university, making the university an employer of choice.

\section{Discussion}

Self-funded leave is a unique form of leave. Employees must commit to a relatively long period of salary contribution before the leave begins. Yet, there are no guidelines imposed on the employee about how leave time is to be used. Due to the time span involved and the flexibility of leave activities, planning and adaptation to changing circumstances are more likely to be issues in self-funded leave than in other types of employer granted leave.

The self-funded leave program investigated in the current research resulted in mostly positive experiences for those who participated. Yet, self-funded leave can be characterized as a series of transitions and transitions are sometimes problematic. Significantly, a number of participants stated that assistance in planning for and coping with transitions before, during, and after the leave would have been desirable. A number of the participants believe, in retrospect, that career counseling would have been beneficial. Yet, although career counseling is available to employees of the university, none of the leave participants utilized it. An implication of the results of this study is that career counseling could provide a meaningful adjunct to employees undertaking selffunded leave.

Goodman, Schlossberg, and Anderson (2006) proposed the 4S (situation, self, support, and strategies) model for helping adults with transitions. Under each element, a number of variables that can either contribute to the ease or to the difficulty of the transition are identified. As self-funded leave involves transitions, the 4S model is 
Self-funded leave and life role development 13

proposed as useful for career counselors who work with clients engaging in self-funded leave.

Results of this study identified financial resources as problematic for many during self-funded leave. Participants voiced that if they had opportunity to better anticipate the realities of receiving $80 \%$ of salary during the lead-up period then the leave period itself would have significantly improved their leave experience. Financial planning assistance is a support that would likely contribute to the overall positive outcome of the leave. Although not usually the expertise of career counselors, they should help those enrolled in self-funded leave programs consider the financial implications. Referral to financial planning services may be necessary.

Finances were an issue not only because of the reduction in take-home salary, but also because participants found that they often increased spending during the leave period for activities such as overseas travel. Financial concerns were often exacerbated when partners (spouses) took unpaid leaves of absences from their employment in order to travel with participants, thereby further decreasing income. Career counselors should assist leave takers in developing effective coping strategies as part of planning for the leave transition (Goodman et al., 2006).

Employees who have already completed a self-funded leave are likely resources who would be useful to those planning for their leave. Participants in the current study suggested that "alumni” of the self-funded leave program would likely provide insights and advice for maximizing the leave experience. Former leave program participants were also proposed by study participants as potential sources of information, especially for those wishing to travel overseas during their leave. Study participants recommended that 
an on-line discussion forum available to current and past leave participants would provide a convenient mechanism for interaction.

Changes in life roles brought on by participating in the leave programs were not easy for some who were interviewed in the study. Changes in relationships with partners (spouses), children, and friends were not always positive. In some cases difficulty in relationships were exacerbated by financial concerns. However, spending more time with family, establishing (or disestablishing) daily routines, or the strain that can develop when traveling with family or friends were significant stressors for some when on leave. Goodman et al. (2006) recognized that personal support is a vital adjunct for easing adult transitions. Study participants identified that when difficulties arose from altered relationships, availability of personal support would have been desirable. In instances when a university is offering self-funded leave, participants could be aided by on-campus resources such as a Career Center or the Counseling Center for coping with role transitions. Especially critical periods of transitional stress are the periods just prior to leaving and returning to employment. Employer provided support at these junctures would be useful for those employees who are experiencing difficulties.

Timing is also identified by Goodman et al. (2006) as a critical consideration for a transition. The importance of timing was echoed by participants of this study. Indeed, some participants altered the commencement of their leave date or the date of return to work due to unforeseen changes in personal circumstances. Self-funded leave programs require a long-term commitment of time due to the period when salary is being saved and the leave period itself. Therefore, flexibility in the conditions of self-funded leave is necessary for employers who offer self-funded leave programs. Employees require 
options to delay the commencement of leave, opt out, or modify the length of leave in response to changes in their personal situations.

\section{Conclusions and Summary}

The results of this study confirm that self-funded leaves of absence are win-win situations for employers and employees. Self-funded leave provides employees with the time to achieve personal and, in some cases, professional goals. The time afforded to an employee by self-funded leave impacts the life roles of the employee and provides the means to increase the salience of roles other than worker (employee). Self-funded leave can therefore be a significant means for establishing work-life balance.

There are apparent benefits to employers who offer self-funded leave to employees. Beyond providing a mechanism for employees to attain work-life balance, employers gain the good will and revitalization of their workforce. Employers who provide self-funded leave are seen as "employers of choice" and can thus have an advantage in attracting new staff. Unlike most other leave programs, self-funded leave requires no financial commitment by the employer. Obviously, employees save their own salaries to draw upon during the leave. Employers benefit from the development of replacement staff when an employee is on self-funded leave. Replacement staff engage in job duties that provide work trials, skills development, and position experience that are useful for organizational succession planning, at no additional cost to the employer.

Despite the attractiveness of self-funded leave, the current study revealed that self-funded leave opportunities are not without potential concerns. Financial difficulties brought on by reduced salary during the lead-up period and the leave itself were problematic for a number of the self-funded leave takers interviewed in this study. 
Self-funded leave and life role development 16

Participants also discussed concerns about modified role relationships at work and with family. Unplanned events occurred during the leave period of most participants.

Flexibility, adaptation, and goal modification were necessary. Although most participants were capable of responding to challenges brought on by the experienced transitions, it was evident that some participants would have benefited from professional services such as career counseling.

Clearly, there are implications for employers who offer self-funded leave. The results of the current study suggest that assistance in the form of career counseling during planning, the leave period itself, and the return to work is desirable for some who are undertaking self-funded leave. Participants suggested that career counseling be part of the self-funded leave program. When self-funded leave is offered by an employer such as a university, career counseling resources are likely to be available on campus. When other types of employers offer self-funded leave, support may be available through human resources offices or through an employee assistance program. 
Self-funded leave and life role development 17

\section{References}

Allen, T., Herst, D., Bruck, C., \& Sutton, M. (2000). Consequences associated with work-to-family conflict: A review and agenda for future research. Journal of Occupational Health Psychology, 5, 278-308.

Auckland University of Technology. (n.d.). Staff handbook. Auckland, NZ: Author.

Benshoff, J., \& Spruill, D. (2002). Sabbaticals for counselor educators: Purposes, benefits and outcomes. Counselor Education and Supervision, 42, 131-144.

Boening, C., \& Miller, M. (1997). Research and literature on the sabbatical leave: A review. (ERIC Document Reproduction Service No. ED 414 777).

Carr, A., \& Tang, T. (2005). Sabbaticals and employee motivation: Benefits, concerns and implications. Journal of Education for Business, 80, 160-165.

Cook, J. (1994). Are you on the cutting edge? Teaching Pre K-8, 24, 28-29.

Gambles, R., Lewis, S., \& Rappoport, R. (2006). From work-life balance to socially sustainable work: An international perspective. London: Work-life Research.

Gaziel, H. (1995). Sabbatical leave, job burnout and turnover intentions among teachers. International Journal of Lifelong Education, 14, 331-338.

Glynn, C., Steinberg, I., \& McCartney, C. (2002). Work-life balance: The role of the manager. Horsham, UK: Roffey Park.

Goodman, J., Schlossberg, N., \& Anderson, M, (2006). Counseling adults in transition: Linking practice with theory ( $3^{\text {rd }}$ ed.). New York: Springer. 
Self-funded leave and life role development 18

Greenhaus, J., \& Beutell, N. (1985). Sources of conflict between work and family roles. Academy of Management Review, 10(1), 76-88.

Greenhaus, J., Collins, K., \& Shaw, J. (2003). The relation between work-family balance and quality of life. Journal of Vocational Behavior, 63, 510-531.

Greenhaus, J., \& Foley, S. (2007). The intersection of work and family lives. In H. Gunz \& M. Peiperl (Eds.), Handbook of career studies (pp.131-152). Thousand Oaks CA: Sage.

Hall, D. (1990). Promoting work/family balance: An organizational change approach. Organizational Dynamics, 18(3), 5-18.

Halpern, D., \& Murphy, S. (2005). From work-family balance to work-family interaction. Mahwah, NJ: Lawrence Erlbaum Associates.

Hubbard, M. (2002). Exploring the sabbatical or other leave as a means of energizing a career. Library Trends, 50, 603-624.

Keleher, K. (1993). Sabbatical leaves for nurse-midwives in clinical practice. Journal of Nurse-Midwifery, 38, 165-167.

Kimball, B. (1978). The origin of the Sabbath and its legacy to the modern sabbatical. Journal of Higher Education, 49, 303-315.

Lobel, S., \& Kossek, E. (1996). Human resources strategies to support diversity in work and personal lifestyles: Beyond the "family-friendly” organization. In E. Kossek \& S Lobel (Eds.), Managing diversity: Human resource strategies for transforming the workplace (pp.221-244). Oxford, UK: Blackwell. 
Self-funded leave and life role development 19

Neault, R. (2005). That elusive work-life balance. Paper presented at the National Consultation on Career Development (NATCON) Canada. Retrieved July 15, 2008, from http://www.natcon.org/natcon/papers/natcon_papers_2005_e5.pdf

Pocock, B. (2003). The work/life collision. Annandale, AU: The Federation Press.

Sima, C. (2000). The role and benefits of the sabbatical leave in faculty development and satisfaction. New Directions for Educational Research, 105, 67-75.

Super, D. (1976). Vocational guidance: Emergent decision-making in a changing society. In Proceedings of the eighth seminar of the International Association for Educational and Vocational Guidance. Lisbon, PT: Sociedade Portuguesa de Psicologia.

Super, D. (1980). A life-span, life-space approach to career development. Journal of Vocational Behavior, 16, 282-92.

Treasury Board of Canada Secretariat. (1997). Self funded leave. Ottawa, ON: Author. Retrieved July 15, 2008, from http://www.tbssct.gc.ca/pubs_pol/hrpubs/leave/dwnld/self_fl_e.rtf

Zahorski, K. (1994). The sabbatical mentor: A practical guide to successful sabbaticals. Bolton, MA: Anker. 